\title{
Article
}

\section{Correlation between the burden of family caregivers and health status of people with diabetes mellitus}

\author{
Niko Dima Kristaningrum, Dian Azizah Ramadhani, Yati Sri Hayati, Setyoadi \\ School of Nursing, Faculty of Medicine, Universitas Brawijaya, Malang, Indonesia
}

\begin{abstract}
Background: Family caregivers play an important role in providing long-term care for people with diabetes mellitus because it is a chronic disease that requires critical attention. This increases the burden of family caregivers which affects the health status of people with this disease. Therefore, the aim of this study is to determine the correlation between the burden of family caregivers and the health status of people with diabetes mellitus.

Design and methods: This is an analytic observational study which was carried out in the work area of public health centers in Malang City using a cross-sectional design approach. The subjects used were 327 people with diabetes mellitus and their families were selected using the cluster sampling technique. Data collection was carried out using demographic data instruments, Zarit Burden Interview (ZBI) questionnaire to measure the burden of family caregivers and the SF 12 questionnaire to measure the health status of people with diabetes mellitus.

Results: The results of the Spermank-Rank statistical test showed that there was a negative relationship between the burden of family caregivers and the health status of people with diabetes mellitus (p-value 0.000 and coefficient value of -0.333).

Conclusions: It was concluded that the lesser the burden on family caregivers, the better the health status of people with diabetes mellitus. Therefore, interventions are needed to reduce the burden of family caregiver and improve the health status of patients with diabetes mellitus.
\end{abstract}

\section{Introduction}

Approximately 415 million people worldwide suffered from diabetes in 2015 and it later increased to 463 million in 2019. It was estimated that the number of people suffering from diabetes mellitus would increase to 578 million by 2030 and 700 million by 2045. ${ }^{1}$ Furthermore, Indonesia was ranked sixth position for DM patients in the word with a total number of 10.3 million in $2017 .^{2}$

Diabetes mellitus (DM) is a chronic degenerative and noncommunicable diseases caused by abnormal insulin secretion and characterized by high blood sugar levels in the body. ${ }^{2}$ Being a chronic disease, diabetes requires long-term treatment and it's sufferers need some changes in their lifestyle, such as adjusting their diet intake, taking medications and exercising regularly. DM patients experience dependence on others because of their decreased mental and physical functions. Therefore, they need to get support from family members in order to carry out their activities that are useful in controlling their blood sugar levels. ${ }^{3}$

The family can act as a family caregiver to help people with T2DM manage their diseases. ${ }^{4}$ A Family caregiver is a family member that provides primary care or help to meet the needs of sick family members. It could be a relative, spouse, adult child, friend, or neighbors that has a personal relationship with the family. Furthermore, they are also individuals that provides various unpaid assistance to someone either suffering from a chronic or debilitated condition, or has limitations in their physical, mental, or cognitive functioning. ${ }^{5}$

A family caregiver is someone that is responsible for providing physical, emotional, and financial supports to family members that are unable to take care of themselves due to illness, injury or disability. ${ }^{6}$ Caregiving is not a new role in the family because people have always provided emotional, physical, and financial support to family members and others that they are close to. What has changed in the past three decades is the number of individuals that take on this role, the duration and intensity of the care provided, and the complexity of the care delivered. ${ }^{6}$ The role or duty of family caregivers include assisting in personal care and mobility, performing caring tasks, performing household duties and solving financial problems. The number of tasks that family caregivers need to perform creates a feeling of burden for them, which is commonly referred to as the caregiver burden. ${ }^{7}$

The high burden of family caregivers makes them susceptible to physical and mental health problems such as sleep difficulties, insomnia, pain, headaches, chest pain and depression. ${ }^{8}$ It was stated in a research that $66.7 \%$ and $22.5 \%$ of family caregivers experience both an objective subjective family burdens when caring for DM patients. Most family members are heavily burdened in caring for DM sufferers due to difficulties in performing longterm home care. Excessive stress, duties and responsibilities experienced by caregivers have a negative impact on DM patients. This is because the stress experienced could be an obstacle in performing their roles as caregivers thereby having a negative impact on

Significance for public health

Families are regarded as the smallest unit of the society consisting of the head and several other people that live together and are dependent on each other. Family members with diabetes mellitus require long-term care and therefore require the assistance of a family caregiver at home. The burden of family caregivers and the health status of people with this diabetes diseases have an impact on morbidity, mortality and the degree of public health. This study contains the basic data of policy made for public health services to improve public health status, especially for people with diabetes mellitus and their family. 
the health status of people with this disease. ${ }^{9}$ The quality of people's life could be used in determining their health status. ${ }^{10}$ Furthermore, the Health-related quality of life (HRQoL) is one of the most widely measured treatment outcomes to self-assess the effects of the management of chronic disease on health. It also used to monitor the physical, psychological and social aspects of personal health that is influenced by an individual expectations, beliefs, perceptions and experiences. ${ }^{11}$ However, for chronic diabetes patients, a complete cure would not be achieved. ${ }^{12}$ Clinical measures could be used to provide a good estimate of disease control, however the ultimate aim of managing diabetes is preventing the patient's QOL from getting worse. ${ }^{12}$ The health status of DM patients need to be measured, because it is the main goal in the treatment of chronic incurable diseases. ${ }^{13}$ The aim of this study is to determine the relationship between the burden of family caregivers and the health status of people with diabetes mellitus in Malang City.

\section{Design and Methods}

This is a quantitative study that made use of observational analytic methods using a cross-sectional design. The population were 1787 diabetes mellitus patients and their family caregivers. The cluster random sampling method was used in collecting data from 327 people with diabetes mellitus and their family caregiver in all of the Public Health Centers in Malang City. The family caregiver inclusion criteria were those that live in the same houses with diabetes mellitus patients, more than 17 years old, could read and write, and understands the Indonesian language. Furthermore, the inclusion criteria for people with diabetes mellitus were those that could read and write, understands the Indonesian language, lives in the same houses with family caregivers, and registered at the public health center as those undergoing outpatient care. Data was collected from January to March 2020 using demographic data instruments, Zarit Burden Interview (ZBI) questionnaires to measure the burden of family caregivers and the SF 12 questionnaire to measure the health status of DM patients. This study got ethical approval from the Health Ethic Committee, Faculty of Medicine, Universitas Brawijaya with ethical clearance number 06/EC/KEPK/01/2020. The participants were given an informed consent before participating in this study.

\section{Results and discussions}

The results showed that the demographic characteristics of family caregivers were mostly less than 45 years $(48.3 \%)$, had high school education (48.6\%), self-employed/private occupation $(57.5 \%)$, and relationships with DM sufferers that are children (47.1\%). It was found that patients with diabetes mellitus based on the demographic characteristics in this study were mostly $45-65$ years old $(63.3 \%)$, females $(80.4 \%)$, had elementary level education $(51.7 \%)$, and not working $(68.8 \%)$. The demographic characteristics of DM clients are shown in Table 1.

The burdens of family caregivers were mostly in the little-no burden category (91.4\%), and none of the respondent experienced any burden in the heavy category. Each domain of the burden of family caregivers showed that the physical burden and family relationships with patients with a value of $97.2 \%$ were placed in the

Table 1. Characteristics of family caregivers and people with diabetes mellitus.

\begin{tabular}{|c|c|c|c|c|}
\hline \multirow[t]{2}{*}{ Demographic characteristics } & \multicolumn{2}{|c|}{ Family caregivers } & \multicolumn{2}{|c|}{ People with diabetes mellitus } \\
\hline & n & $\%$ & n & $\%$ \\
\hline \multicolumn{5}{|l|}{ Age } \\
\hline$<45$ years old & 158 & $48.3 \%$ & 7 & $2.1 \%$ \\
\hline 45-65 years old & 123 & $37.6 \%$ & 207 & $63.3 \%$ \\
\hline$>65$ years old & 46 & $14.1 \%$ & 113 & $34.6 \%$ \\
\hline \multicolumn{5}{|l|}{ Gender } \\
\hline Male & 168 & $51.4 \%$ & 64 & $19.6 \%$ \\
\hline Female & 159 & $48.6 \%$ & 263 & $80.4 \%$ \\
\hline \multicolumn{5}{|l|}{ Last education } \\
\hline No school & 1 & $0.3 \%$ & 2 & $0.6 \%$ \\
\hline Elementary school & 71 & $21.7 \%$ & 169 & $51.7 \%$ \\
\hline Middle school & 54 & $16.5 \%$ & 76 & $23.2 \%$ \\
\hline Senior high school & 159 & $48.6 \%$ & 65 & $19,9 \%$ \\
\hline Undergraduate or postgraduate & 42 & $12.8 \%$ & 15 & $4.6 \%$ \\
\hline \multicolumn{5}{|l|}{ Occupation } \\
\hline Not employed & 120 & $36.7 \%$ & 225 & $68.8 \%$ \\
\hline Labor & 9 & $2.8 \%$ & 3 & $0.9 \%$ \\
\hline Farmers & 1 & $0.3 \%$ & 0 & $0 \%$ \\
\hline Civil servants & 7 & $2,1 \%$ & 3 & $0.9 \%$ \\
\hline Army / police & 2 & $0.6 \%$ & 1 & $0.3 \%$ \\
\hline Others & 188 & $57.5 \%$ & 95 & $29.1 \%$ \\
\hline \multicolumn{5}{|l|}{ Relationship } \\
\hline Husband and wife & 153 & $46.8 \%$ & & \\
\hline Child & 154 & $47.1 \%$ & & \\
\hline Son in law & 3 & $0.9 \%$ & & \\
\hline Sister & 6 & $1.8 \%$ & & \\
\hline Niece & 1 & $0.3 \%$ & & \\
\hline Grandchild & 9 & $2.8 \%$ & & \\
\hline Mother & 1 & $0.3 \%$ & & \\
\hline
\end{tabular}


low category. Furthermore, the economic burden had a low value of $99.4 \%$. All the respondents were placed in the low category in the social burden domain, and $99.7 \%$ in the emotional burden domain (Table 2).

The health status of people with DM were mostly in the good health status category $(90.8 \%)$. Each domain of health status, on the physical dimensions consisting of physical function and role, body pain and general health perception mostly had values in the good category of the physical function domain (94.8\%) (Table 3). Furthermore, the not good category of physical dimensions had the highest value in the domain of public health perception. The mental dimensions consist of emotional roles, vitality, mental wellbeing and social functions and had values in the good category of the mental welfare domain (98.8\%), while the not good category of the mental dimension had the highest value in the vitality domain (29.7\%).

Table 4 showed the majority of family caregivers in the no-little burden category and people with DM that had good health sta- tus $(85.3 \%)$. Furthermore, $6.1 \%$ of family caregivers were in the no-little burden category in conjunction with people suffering from DM that had poor health status. The Spearman-Rank test results found a correlation between the burden of caregivers and the health status of people with diabetes mellitus $(p=0.000)$. Based on the results of the statistical tests, a coefficient value -0.333 was obtained which means that the lesser the burden on family caregivers, the better the health status of people with diabetes mellitus and vice versa with moderate correlation (Table 5).

The results showed that $91.4 \%$ of family caregivers were in the no-little burden category. Furthermore, the burden of family caregivers is influenced by several factors such as age, sex, education level and job. ${ }^{5}$ The family caregivers in this study were mostly less than 45 years old of which at that age they still have a strong physic and are capable of regulating their emotions in order for them to perform their duties well. The majority of respondents were males with low burdens because men have an aggressive nature and tend to be rational compared to women. This supported

Table 2. Domain of family caregiver burden.

\begin{tabular}{|c|c|c|c|c|}
\hline \multirow[t]{2}{*}{ Domain } & \multicolumn{2}{|c|}{ Low } & \multicolumn{2}{|c|}{ High } \\
\hline & n & $\%$ & n & $\%$ \\
\hline \multicolumn{5}{|l|}{ Objective burden } \\
\hline Physical & 318 & $97.2 \%$ & 9 & $2.8 \%$ \\
\hline Economy & 325 & $99.4 \%$ & 2 & $0.6 \%$ \\
\hline Social & 327 & $100 \%$ & 0 & $\%$ \\
\hline Relationship with patients & 318 & $97.2 \%$ & 9 & $2.8 \%$ \\
\hline Subjective burden & & & & \\
\hline Emotional & 326 & $99.7 \%$ & 1 & $0.3 \%$ \\
\hline
\end{tabular}

Table 3. Domain of health status of people with diabetes mellitus.

\begin{tabular}{|c|c|c|c|c|}
\hline \multirow[t]{2}{*}{ Domain } & \multicolumn{2}{|c|}{ Low } & \multicolumn{2}{|c|}{ High } \\
\hline & n & $\%$ & n & $\%$ \\
\hline \multicolumn{5}{|l|}{ Physical dimension } \\
\hline Physical function & 310 & $94.8 \%$ & 17 & $5.2 \%$ \\
\hline Physical role & 279 & $85.3 \%$ & 48 & $14.7 \%$ \\
\hline Body pain & 296 & $90.5 \%$ & 31 & $9.5 \%$ \\
\hline General perception & 182 & $55.7 \%$ & 145 & $43.3 \%$ \\
\hline \multicolumn{5}{|l|}{ Mental dimension } \\
\hline Emotional role & 301 & $92 \%$ & 26 & $8 \%$ \\
\hline Vitality & 230 & $70.3 \%$ & 97 & $29.7 \%$ \\
\hline Mental wellness & 323 & $98.8 \%$ & 4 & $1.2 \%$ \\
\hline Social function & 321 & $98.2 \%$ & 6 & 1.8 \\
\hline
\end{tabular}

Table 4. Cross-tabulation of the burden of family caregivers and the health status of diabetes mellitus patients.

\begin{tabular}{|c|c|c|c|c|c|}
\hline \multirow[t]{3}{*}{ Cross-tabulation } & & \multicolumn{4}{|c|}{ Health status of people with diabetes mellitus } \\
\hline & & \multicolumn{2}{|c|}{ Good } & \multicolumn{2}{|c|}{ Not good } \\
\hline & & n & $\%$ & n & $\%$ \\
\hline \multirow[t]{2}{*}{ Family caregiver burden } & No-little burden & 279 & $85.3 \%$ & 20 & $6.1 \%$ \\
\hline & Mild to moderate burden & 18 & $5.5 \%$ & 10 & $3.1 \%$ \\
\hline
\end{tabular}

Table 5. Correlation analysis between the burden of family caregivers and the health status of diabetes mellitus patients.

\begin{tabular}{lcc} 
Variable & Correlation coefficient \\
Family caregiver burden-health status & 0.000 & -0.333 \\
\hline
\end{tabular}


by study in Nigerian that caregivers of patients with Type 2 diabetes mellitus experience burden and psychological distress associated with caregiving, especially female caregivers and those taking care of those taking care of patients with complications. ${ }^{14}$ In addition, the level of education also affects the burden of caregivers. This is because it determines their workload when caring for sick family member. Caregivers who were less educated and caring for patients with more recent illness appeared relatively vulnerable. ${ }^{15}$

The burden of caregivers is divided into two, namely objective and subjective. The objective load consists of physical, economic, social burdens, and family relationship with the patient. While the subjective consists of only emotional burden. ${ }^{16,17}$ Physical burden seen from the caregiver's health becomes disrupted when caring for family member with DM. Furthermore, $97.2 \%$ of the family caregivers had a physical burden in low category. This is because $48.3 \%$ of family caregivers that are less than 45 years still carry out daily activities independently. Economic burden is defined as financial problems faced by family caregivers when caring for people with DM. 99.4\% of family caregivers experienced economic burdens in the low category because $57.5 \%$ of them work as private entrepreneurs. Social burden is defined as the issue on whether family caregivers do not have time to interact with friends or neighbors such as attending social gathering or other activities. All the family caregivers had low social burden when caring for family member with DM and were still actively participating in social activities or going out with friends. This is because their family members suffering from DM had no complications and did not require excessive supervision.

Family relationships with members suffering from DM is mainly based on whether they are able or unable to provide better care for them. Family plays a major role in the management of diabetes. Family members can actively support and care for patients with diabetes. ${ }^{18}$ Their supportive behaviors are perceived by their family members diagnosed with T1DM, but there has been no optimal association with disease control. However, the involvement of the family can aid in decreasing possible complications of the disease by intervening in critical situations. ${ }^{19}$

Furthermore, $44.3 \%$ of family caregiver stated that they are able to provide better care for family members with DM and also stated that it is an obligation whenever their family members need more help. ${ }^{4}$ Emotional burden is defined as the problems faced by family caregivers when caring for family members with DM and they include stress, anger, and fear. Furthermore, $99.7 \%$ of the family caregivers experienced emotional burden in the low category, and $68.6 \%$ had feelings of fear for the future of family member with DM, because it is an incurable disease and has various complications when not properly controlled. This result is different from several journals which stated that $34.1 \%$ and $31.8 \%$ of family members with DM that were placed in the low category experienced both subjective and objective burdens. ${ }^{20}$ The results of the journal research obtained from the analysis of the family burden of patients with type $2 \mathrm{DM}$ stated that $66.7 \%$ experienced objective burdens in the heavy category, while $70.6 \%$ experienced subjective burdens in the moderate category. ${ }^{21}$

Recent studies have shown that most people with DM have good health status. However, some factors that may affect their health status include sex, age, education, length of suffering, and occupation. Aging makes it difficult to control blood sugar levels because of the decline in the function of body organs. Female DM patients are more common than men because women experience menopause, therefore the estrogen and progesterone hormones make the cells respond to insulin. The health status of people with DM could be improved depending on their high level of education. ${ }^{22}$ In addition, suffering from DM for a long period of time could also affect the health status and anxiety levels of an individual. ${ }^{23}$ Apart from these factors, the health status of people with DM could also be seen from their blood sugar levels. Therefore, patients need to maintain their blood sugar levels, especially when is within the normal score $(<200 \mathrm{mg} / \mathrm{dL})$ in order to avoid complications.

The health status of an individual consists of physical and mental dimensions. The physical dimensions consist of physical functions and roles, body pain, general health perception, while the mental dimensions consist of emotional roles, vitality, mental wellbeing and social functions. The physical function is seen when performing light activities such as leisure walking and climbing stairs whether it is limited or not; $94.8 \%$ of people with DM had physical functions in the good category. Furthermore, the physical roles are seen when carrying out a work that could either be completed on time or not, and $85.3 \%$ of people with DM had physical functions in the good category. Body pains are usually felt when carrying out daily activities, and $90.5 \%$ of people with DM that had body pains were in the good category. General health perception is seen from current situations, and $55.7 \%$ of people with DM with this function were placed in the good category. ${ }^{24}$

Mental dimensions consist of emotional roles, vitality, mental well-being and social functions. The emotional roles are seen from feelings of anxiety, sadness or distress influence activity, and $92 \%$ of people with DM that had emotional roles were placed in the good category. Vitality is seen from whether DM sufferers feel that they have a lot of energy. Furthermore, $70.3 \%$ of DM sufferers that had vitality were placed in the good category. Mental well-being is seen from whether DM sufferers either feel calm or hopeless, and $98.8 \%$ that had mental well-being were placed in the good category. Social functions are seen from activities such as visiting friends and neighbors, and $98.2 \%$ of people with DM had social functions in the good categories.

Majority of the family caregiver did not have values in no-little burden category, while health status of people with DM were placed in the good category. The results showed that there was a negative relationship between the burdens of family caregivers and the health status of people with DM. This means that the lesser the burden on family caregivers, the better the health status of people with diabetes mellitus. It also proves that the role of caregivers does not fully affect the health status of DM sufferers. The health status of people with DM is seen from their blood sugar levels, and when its above the normal level or $>200 \mathrm{mg} / \mathrm{dL}$ it is regarded not favorable. With proper management of DM, blood sugar levels could be controlled by its sufferers and this include maintaining dietary patterns, performing regular physical activities, searching for information about DM and diligently controlling their blood sugar levels and taking medication regularly. ${ }^{25}$

The results on physical dimensions had sub-components including 43.4\% physical function, $93.3 \%$ physical role, $36.7 \%$ body pain and $60 \%$ general health perception, and they all had unfavorable categories. The physical role had the highest score in the unfavorable category on the physical dimension. Furthermore, $56.7 \%$ of the DM patients with ages greater than 65 years could not finish their work on time because they have entered the elderly phase. This phase is characterized by a decrease in physical health which results in DM sufferers becoming tired easily and not completing their work on time.

Mental dimensions have sub-components which include $66.7 \%$ emotional role, $43.3 \%$ vitality, $13.3 \%$ mental well-being, and $20 \%$ social function. Emotional role had the highest score in the unfavorable category whereby the feeling of anxiety/sadness made the DM sufferers not to complete their work. This is because 
$56.7 \%$ of them were above 65 years old and have entered the elderly phase where they experience changes physically, and psychologically. Adherence to consuming drugs is one of the efforts to control blood glucose level or complications that may result. The success of treating DM apart from using medical procedures such as drug administration is also influenced by diet and exercise patterns to maintain physical fitness. These results are in line with other researches. Furthermore, $41.5 \%$ of people with DM have normal blood sugar levels that is greater than $160 \mathrm{mg} / \mathrm{dL}$ with adherence to taking medications. ${ }^{24}$

In the elderly phase there is a decrease in muscle tone, resulting in the elderly easily fatigued, therefore it is necessary to utilize program activities. Furthermore, chronic disease control program at the health center consists of joint exercise, counseling and blood sugar control which is very necessary for people with DM. This is in line with other research whereby $50.9 \%$ of DM patients diligently carried out exercises and had normal blood sugar levels $<160$ $\mathrm{mg} / \mathrm{dL} 16$. Regular exercise is very good in regulating blood glucose level, losing weight and also increase HDL cholesterol levels. ${ }^{20}$ Diabetes exercise should be carried out by DM patients, because it improves all organs of the human body.

Families that render care to their relations suffering from DM stated that they do not feel burdened when carrying out their duties as caregivers because they consider caring for one another as a family task. Families remain active in their social activities with other communities such as social gatherings and treating DM sufferers does not affect this. The burden felt by each caregiver is different because it is influenced by their various perceptions. Furthermore, playing the role of a family caregiver could have a positive or negative impact. Positive influences that arise include being able to improve relationships with sufferers, increasing sense of responsibility, and sharing love and support with them. These results are in line with other studies that found that being a caregiver also increases their personal development and self-esteem.

The burden of a family caregiver increases the susceptibility of physical and mental health problems such as sleep difficulties, insomnia, pain, headaches, chest pain and depression. ${ }^{5}$ Caregiver stress was negatively associated with physical and mental health. Physical health was positively associated with family/community connectedness and mental health was positively associated with both family support and connectedness. ${ }^{26}$ The number of tasks and responsibilities, pressure and stress experienced by caregivers in caring for people with DM would have a negative impact on the patients, because stress experienced can be an obstacle in performing the role of a family caregiver and will have an impact on the health status of DM sufferers. ${ }^{8}$

\section{Conclusions}

It was concluded that a negative and moderate correlation exist between the burden of family caregivers and the health status of people with DM that means the lesser the burden on family caregivers, the better the health status of people with diabetes mellitus. Therefore, interventions are needed to reduce the burden of family caregiver and improve the health status of patients with diabetes mellitus.
Correspondence: Niko Dima Kristianingrum, School of Nursing, Faculty of Medicine, Universitas Brawijaya, Jl. Puncak Dieng, Kunci, Kalisongo, Kec. Dau, Malang, East Java 65151, Indonesia.

Tel. +62.341569117 - Fax: +62.341564755

E-mail: nikodima.fk@ub.ac.id

Key words: Burden; family caregiver; health status; diabetes melitus.

Acknowledgment: The author is grateful to the Faculty of Medicine, Universitas Brawijaya for their support and encouragements during this study, and also to the Malang City Health Office and participants.

Contributions: All authors contributed equally to this article, and have also read and approved the final manuscript.

Conflict of interests: The author declares no potential conflict of interest.

Funding: Faculty of Medicine, Universitas Brawijaya, Malang, Indonesia.

Ethics approval: This study has been approved by the Health Research Ethics Committee of the Faculty of Medicine, Universitas Brawijaya, Malang, Indonesia, with ethical clearance number 06/EC/KEPK/01/2020

Conference presentation: Part of this study was presented at the $1^{\text {st }}$ International Nursing and Health Sciences Symposium, November $13^{\text {th }}$ to $15^{\text {th }} 2020$, Brawijaya University, Malang, Indonesia.

Received for publication: 14 January 2021.

Accepted for publication: 22 March 2021.

o Copyright: the Author(s), 2021

Licensee PAGEPress, Italy

Journal of Public Health Research 2021;10:2227

doi:10.4081/jphr.2021.2227

This work is licensed under a Creative Commons Attribution NonCommercial 4.0 License (CC BY-NC 4.0).

\section{References}

1. International Diabetes Federation. IDF Diabetes Atlas. 9th ed. Brussels: International Diabetes Federation; 2019.

2. International Diabetes Federation. IDF Diabetes Atlas. 7th ed. Brussels: International Diabetes Federation; 2017.

3. Anizar RDS, Pudjiastuti E. [Studi Deskriptif Mengenai Resiliensi Istri sebagai Caregiver pada Penderita Diabetes Mellitus (DM) Tipe II di RSUD Sejiran Setason (Descriptive study regarding the resilience of wives as caregivers in type II diabetes mellitus (DM) patients at the Sejiran Setason Regional Hospital)].[Article in Indonesian with English abstract]. Prosiding Psikologi 3:1-6. Available from: https://docplayer.info/63199146-Prosiding-psikologi-issn.html

4. Fadilah N, Kusnanto, Nursalam, Rahariyani LD. Analysis of influencing factors of burden of caregiver among stroke patients at home. J Public Health Africa 2019;10:1188.

5. Schulz R, Beach SR, Czaja SJ, et al. Family caregiving for older adults. Annu Rev Psychol 2020;4:635-59.

6. Annisa F. Burden of family caregiver. Belitung Nurs J 2016;2:10-18.

7. Goodhead A, McDonald J. Informal caregivers literature review: A report prepared for the National Health Committee. Health Services Research Centre, Victoria University of Wellington; 2007. Available from: https://www.moh. 
govt.nz/notebook/nbbooks.nsf/0/fb327285c9043995cc257345 00069193/\$FILE/informal-caregivers-literature-review.pdf

8. Gupta S, Isherwood G, Jones K, et al. Assessing health status in informal schizophrenia caregivers compared with health status in non-caregivers and caregivers of other conditions. BMC Psychiatry 2015;15:162.

9. Given BA, Given CW, Sherwood PR. Family and caregiver needs over the course of the cancer trajectory. J Support Oncol 2012;10:57-64.

10. Gibney MJ, Margetts BM, Kearney JM, et al. [Gizi Kesehatan Masyarakat (Public health nutrition)].[Book in Indonesian]. Jakarta: EGC; 2009.

11. Megari K. Quality of life in chronic disease patients. Health Psychol Res 2013;1:e27.

12. Saleh F, Ara F, Mumu SJ, et al. Assessment of health-related quality of life of Bangladeshi patients with type 2 diabetes using the EQ-5D: a cross-sectional study. BMC Res Notes 2015;8:497.

13. Mandagi AM. [Faktor yang Berhubungan Dengan Status Kualitas Hidup Penderita Diabetes Mellitus (Factors associated with quality of life status of diabetes mellitus patients)].[Thesis in Indonesian]. Surabaya: Universitas Airlangga; 2010.

14. Ogunmodede AJ, Abiodun O, Makanjuola AB, et al. Burden of care and psychological distress in primary caregivers of patients with type -2 diabetes mellitus in a tertiary hospital in Nigeria. Ethiop J Health Sci 2019;29:697-708.

15. Awadalla AW, Ohaeri JU, Al-Awadi SA, et al. Diabetes mellitus patients' family caregivers' subjective quality of life. J Natl Med Assoc 2006;98:727-36.

16. Stuart GW. Principle and practice of psychiatric nursing. St. Louis: Mosby Elsevier; 2009.

17. Joanna Briggs Institute. Caregiver burden of terminally-ill adults in the home setting. Nurs Health Sci 2012;14:435-7.

18. Baig AA, Benitez A, Quinn MT, et al. Family interventions to improve diabetes outcomes for adults. Ann N Y Acad Sci
2015; 1353:89-112.

19. AlHaidar AM, AlShehri NA, AlHussaini MA. Family support and its association with glycemic control in adolescents with type 1 diabetes mellitus in Riyadh, Saudi Arabia. J Diabetes Res 2020;2020:5151604.

20. Sari IP, Hidayati H. [Beban Keluarga Dalam Merawat Anggota Keluarga dengan penyakit Diabetes Mellitus di Aceh (Family burden in caring for family members with diabetes mellitus in Aceh)].[Article in Indonesian]. Jurnal Ilmiah Mahasiswa 2016;1:435-7.

21. Adianta IKA, Wardianti GA. [Beban Keluarga Pada Penderita Diabetes Melitus Tipe II (Family burden in type II diabetes mellitus patients)].[Article in Indonesian]. JRKN 2018;2:8590.

22. Gautam Y, Sharma AK, Agarwal AK, et al. A cross-sectional study of QOL of diabetic patients at tertiary care hospitals in Delhi. Indian J Community Med 2009;34:346-50.

23. Reid MKT, Walker SP. Quality of life in Caribbean youth with diabetes. West Indian Med Journal 2009;58:1-8.

24. Hakim BH, Abdullah AZ, Hanis M. [Analisis Faktor Risiko Diabetes Melitus tipe 2 di Puskesmas Tanrutedong, Sidenreg Rappan (Analysis of risk factors for type 2 diabetes mellitus at Puskesmas Tanrutedong, Sidenreg Rappan)].[Article in Indonesian]. Medika: Jurnal Kedokteran Indonesia 2009;35:228.

25. Putri NHK. [Hubungan Empat Pilar Pengendalian DM Tipe 2 dengan Rerata Kadar Gula Darah di Puskesmas Pacar Keling Surabaya (The relationship of the four pillars of type 2 DM control with average blood sugar levels at Pacar Keling Health Center, Surabaya)].[Article in Indonesian]. Surabaya: Universitas Airlangga, 2013.

26. Coser A, Sittner KJ, Walls ML, et al. Caregiving stress among American Indians with type 2 diabetes: The importance of awareness of connectedness and family support. J Fam Nurs 2018;24:621-39. 